Vantage: Journal of Thematic Analysis

ISSN: 2582-7391

A Multidisciplinary Publication of Centre for Research,

Maitreyi College, University of Delhi

April 2020, Volume 1, Issue 1

Original Research Article

\title{
A Sociological Study of the Stigma and Silences around Menstruation
}

Anurita Jalan, Himansha Baweja, Mehar Bhandari, San Kahmei and Aruna Grover*

Department of Sociology, Maitreyi College, Chanakya Puri, New Delhi 110021

*Correspondence: agrover@maitreyi.du.ac.in

\begin{abstract}
In most Southeast Asian countries, menstruation is surrounded by various cultural and religious taboos. In India too, menstruation is a tabooed topic, surrounded by silence and secrecy. The main sources of information about menstruation for young girls are their mothers, sisters and friends. However, due to the shame associated with it, such information is often partial and incorrect. This often has adverse effects on the mental, physical and reproductive health of young girls in India. Millions lack the facilities and resources they need for menstrual hygiene. This paper focuses on the need to break the stigma and silences around menstruation. It emphasizes the need to shift focus to health and hygiene practices of women in India.
\end{abstract}

Keywords: menstruation, hygiene, taboos, gender, patriarchy, health.

\section{INTRODUCTION}

\subsection{About Menstruation}

Menstruation is a biological process that women go through every month. It is traumatic, painful and inconvenient. Social and cultural taboos associated with it negatively impact the physical, mental and social health of women. There are many aspects of its management which need to be observed through the lens of sociology. The medicalization of menstruation, the social and cultural taboos surrounding it, and the commercialization of its management are the aspects often studied in the sociology of health and medicine.

Of the 355 million menstruating women in India, only 12 percent use sanitary pads (Nielsen, 2010). Women in India are forced to manage menstruation using cloth, ashes, newspaper etc. which are extremely unhygienic and often cause various problems. "The reason for this is not just economic distress, but also because they never question the taboos and practices that surround menstruation, which leads to health issues and even death in many cases. "early 90 percent of Indian women don't use sanitary pads" (George, 2016). According to George, 23 
percent of Indian girls drop out of school when they reach puberty, not only because of the stigma attached to periods. Women in India also lack access to hygienic means to manage their menstrual cycles (George, 2016).

Poor menstrual hygiene can cause fungal infections, Reproductive Tract Infections (RTI) and Urinary Tract Infections (UTI). Unhygienic practices also leave women vulnerable to infertility. 'Over 88 percent of women resorted to shocking alternatives such as newspapers, ashes and husk during menstruation, thereby causing severe reproductive health problems. Incidence of RTI was 70 percent more common among women with unhygienic sanitary practices. About 97 percent gynecologists, in a survey, explained that sanitary pads can act as a preventive measure against reproductive tract infections. The biggest barrier to adoption of quality sanitary pads in India turned out to be 'affordability' and 'accessibility'. "Nearly seventy percent of women said that their families cannot afford sanitary pads" (Torondel et al., 2018). Not only during the heavier days but even when women experience a light blood flow, the blood gets contaminated as the pad is damp. Bacteria tend to multiply in moist and warm conditions and this could lead to vaginal infections, urinary tract infections, skin rashes, and more (Times of India, March 06, 2018).

According to Garg, Sharma and Sahay, most young girls in India between the age group 15 and 24 years did not receive any information before the onset of menstruation, which made menarche a traumatic experience for them. One out of three girls in Southeast Asia had no knowledge of menstruation before getting their first period (Garg et al., 2001). 48 percent girls in Iran and 10 percent girls in India believe that getting your period is some kind of disease (UNICEF, 2018). Mothers were uncomfortable in providing information to their daughters, especially before menarche (Garg et al., 2001). Though school curricula in India do not include sex education, they do have human reproduction as part of the syllabi in middle school, but the classroom teaching of this topic is often skipped by teachers, who feel too embarrassed to deal with the topic in a room full of teenagers. So, despite their curiosity and the information being available in the textbooks, adolescents rarely get any information about menstruation from a responsible adult in an unbiased and scientific manner.

\subsection{Menstruation in Anthropology and Sociology literature:}

Mead, in her eminent ethnographic study on Samoa, shows how menstruation is seen as a normal part of life, and there are no taboos or anxieties associated with it. Girls are not taught to look at it as an experience full of dread and distress and thus their experience is not stress, despite the fact that some of them may experience bodily pain or discomfort. They look at 
menstruation as a part of life, and it does not affect their daily routine. Menstruation is not perceived by the Samoan people as a period of distress, nor is it glorified (Mead, 1928). When we compare this to the scenario of Indian women one can see what adds to the "experience of distress".

Many primitive cultures associate menstrual blood with great powers, especially black magic. Durkheim argued that human religion emerged originally in connection with menstruation. His argument was that collective ritual action could establish simultaneously the institutions of totemism, law, exogamy and kinship in addition to distinctively human language and thought. Everything began, according to Durkheim, when a flow of blood periodically ruptured relations between the sexes. "All blood is terrible", he observed, "and all sorts of taboos are instituted to prevent contact with it." During menstruation, females would exercise a "type of repulsing action which keeps the other sex far from them." This same blood was thought to run through the veins of women and animals alike, suggesting the blood's ultimate origin in 'totemic'-parthuman, part-animal - ancestral beings. Once menstrual blood had been linked with the blood of the hunt, it became logically possible for a hunter to respect certain animals as if they were his kin, this being the essence of 'totemism'. Within the group's shared blood resided its 'god' or 'totem', "from which it follows that the blood is a divine thing. When it runs out, the god is spilling over" (Durkheim, 1961).

\subsection{Religion and the taboos around Menstruation}

Without exception all religions place restrictions on menstruating women. Menstrual blood is considered polluting, but at the same time, also very powerful, in terms of witchcraft and sorcery in many cultures.

In Hindu mythology there are various stories related to why women menstruate. In one such story, women took upon themselves the sin of Indra i.e. the accusation of killing a Brahmin, because of which women menstruate once a month. They incurred the sin of killing a Brahmin, and so are considered impure and polluting during their periods (Chowdhary, 2014). For example, in some Hindu communities, women are supposed to stay outside the main home, not enter the kitchen, cook, touch pickles, or eat non-vegetarian food. They are debarred from all social interactions. Traditionally, in South India, the Ritu Kala Samskara ceremony or Ritushuddhi is a ceremony performed after menarche (first menstruation) as celebration of a girl's rite of passage and she is deemed a young woman both physically and spiritually (Jensen, 2015). A feast is organized for the kin group and the villagers, so as to announce that the girl 
is now eligible for marriage, and suitable proposals are welcome. While child marriage has long been given up as a practice in these communities, this ritual is still practiced by many. Hindu belief and practice has carried over into some categories of Buddhist culture, under the influence of which, menstruating women cannot meditate, nor can they have contact with priests. They cannot take part in ceremonies such as weddings. Even in Islam there are prohibitions upon the menstruating woman. First, she may not enter any shrine or mosque. She may not pray or fast during Ramadan while she is menstruating. She may not touch The Qur'an or even recite its contents. She is not allowed to have sexual intercourse for seven days (beginning when the bleeding starts). She is exempted from rituals such as daily prayers and fasting, although she is not given the option of performing these rituals (Kaundal and Thakur, 2014). These laws are derived from the Qur'an (2:222), which reads, it is an illness so let women alone at such times and go not into them till they are cleansed (Ghai, 2015).

The menstrual taboo has been a major reason that women are kept away from positions of authority in the Church. Some Christian denominations advice women not to receive communion, perform prayers and fasting during their menstrual periods. Judaism has the strictest views on the matter. Jewish law forbids any physical contact between a male and female during the days of menstruation and for a week thereafter. On the other hand, Sikhism is the most liberal of all religions in this regard. Guru Nanak, the founder of Sikhism, condemned the practice of treating women as impure while menstruating (Kaundal and Thakur, 2014).

\subsection{Rationale of the study}

This study seeks to sociologically analyze the various social, cultural and practical aspects of menstruation and examine the attitudes and beliefs related to menstruation among young women in urban India. The study focuses on the management, hygienic practices, stigma and taboos associated with menstruation.

The study focuses on women of two different economic strata - the middle income group and the lower income group - as the challenges faced by women in these strata vary significantly. The aim was also to examine the role of social media in generating awareness about menstrual hygiene and breaking various taboos. The lack of knowledge about menstruation affects the health and well-being of women. These problems are generally ignored by not only the women themselves, but also their families. The reason for this is partially economic but religious and cultural taboos associated with menstruation are also responsible for the silences around menstruation. The media through its efforts to spread information about menstruation and 
breaking taboos, whether religious or cultural, has attained commendable results, yet has not been able to affect substantial change.

\section{METHODOLOGY}

\subsection{Methods}

The methodology of the study consists of structured interviews of women. The data collected was qualitative as well as quantitative, the focus being on qualitative data. The target group was women of the age range of 16 to 40 years living in Delhi NCR. The total number of respondents was 44 , out of which 34 belonged to the middle income group, whereas 10 belonged to the lower income group. 3 gynecologists and 1 nurse were also interviewed to get a biomedical perspective on the matter.

\subsection{Ethical Considerations}

All the respondents were assured of complete confidentiality, so wherever the respondents are quoted, their names have been changed in the text. Also, after the interview, the researchers shared the correct scientific information about the biological process of menstruation, the importance of using hygienic sanitary protection, frequent changing of the same, importance of cleanliness, disposal of sanitary napkins, as well as alternative materials available for menstrual management with the respondents.

\section{RESULTS}

\subsection{Age of the respondents}

In the sample, almost 30 percent respondents were from the age group of 16 to 19 years, whereas almost 60 percent respondents were from the age group of 20 to 29 years. Graph 1 depicts the age groups that the respondents belong to. About 10 percent respondents are from the age group of 30 to 40 years (Graph 1). As most of the respondents were young (like the research investigators), they were comfortable discussing personal issues.

\subsection{Socio-economic class of the respondents}

While 22.7 percent respondents are from lower income group, 77.3 percent belong to middle income group. This is depicted visually in graph 2. Some of the women, especially the older ones, from the lower income group tend to use cloth. While the women from the middle class were more concerned about the taboos, those from the lower class were more concerned about the cost of sanitary napkins. 


\subsection{Religion of the respondents}

The sample consists of 86.4 percent Hindu women, 2.3 percent Muslims, 9.1 percent Christians and 2.3 percent Buddhist. Graph 3 depicts the various religions the respondents belong to. Most respondents, except the Sikh women, followed the taboos of menstruation prescribed by their religion. They did not visit temples, mosques, etc. during these times. Some of them shared that they were hesitant to go to these holy places when they felt so defiled and impure. Most respondents followed these restrictions without questioning or doubting them. These were seen as sacred rules ordained by religion, which must be obeyed. Knowledge of the biological processes does little to diminish religious taboos. Not only women who have studied biology at school and college, but even the gynecologists interviewed followed many of the taboos associated with menstruation. In fact, the doctor also justified these taboos saying that they provide much needed rest to housewives. There were very few respondents who did not observe any of the religious restrictions.

Graph 1: Respondents by age

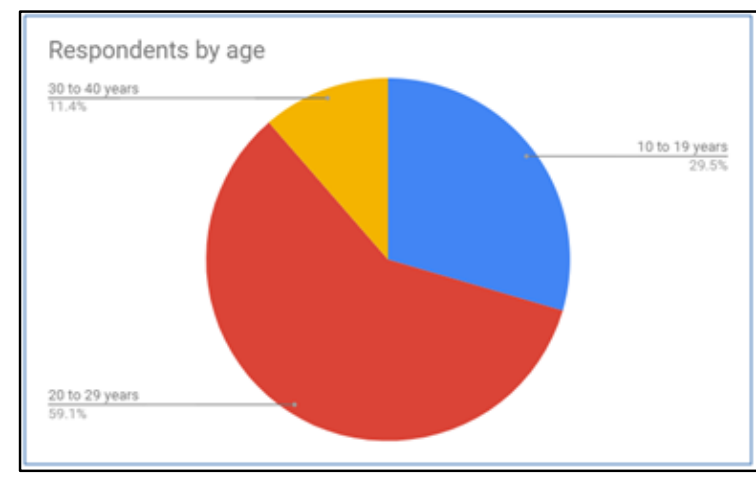

Graph 3: Religion of the Respondents

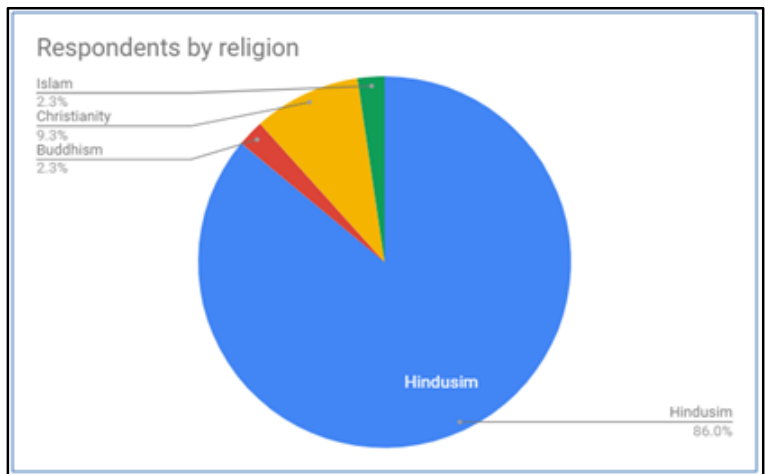

Graph 2: Respondents by income group

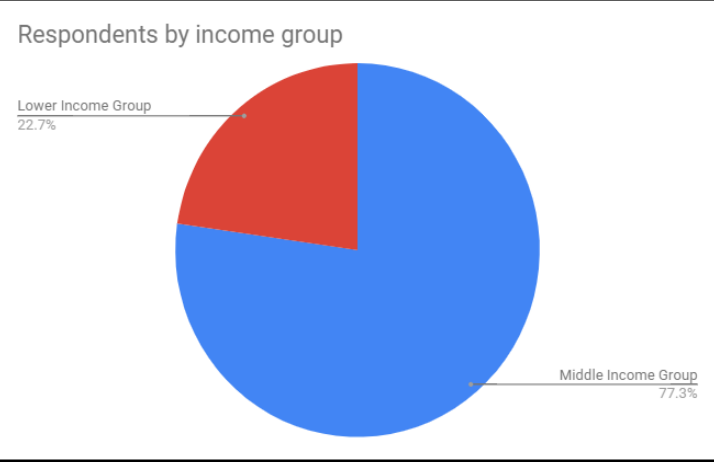

Graph 4: Age at menarche

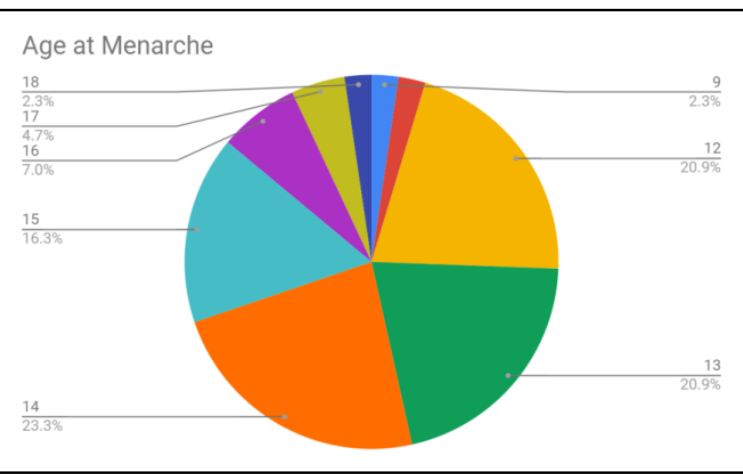




\subsection{Age at Menarche}

Most of the respondents had menarche at the age of 14 years -23.3 per cent. Respondents who started menstruating at the ages of 12 constituted 20.9 per cent of the respondents. The highest age of menarche in this sample of women was $18-2.3$ per cent. Graph 4 depicts the various religions the respondents belong to. As has been often observed, the older women reported later ages of menarche, and the younger girls had a lower age. The age of menarche is reducing, and girls as young as 9 years are experiencing their first menstrual period. In the present sample, the lowest age of menarche is nine years.

\subsection{Knowledge about menstruation prior to menarche}

There were 52 percent respondents who were unaware of menstruation prior to their first experience, and were extremely scared and shocked.

Graph 5 shows respondents who were aware of menstruation at menarche, and those who were not. One girl said she was scared she was 'dying of some terrible disease'. Another one thought she had incurred an injury, though she could not figure out how it could have happened. Most of the mothers had themselves not been educated about menstruation in advance, and they followed the same practice with their daughters.

Graph 5: Awareness of menstruation prior to menarche

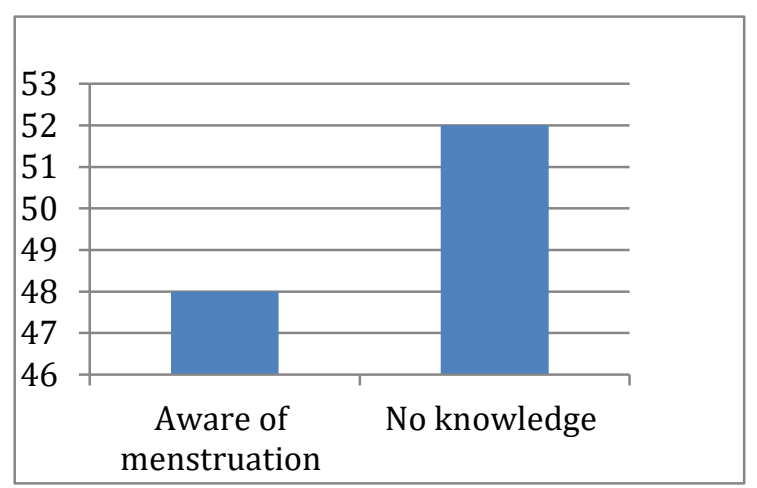

Graph 6: First source of information about menstruation

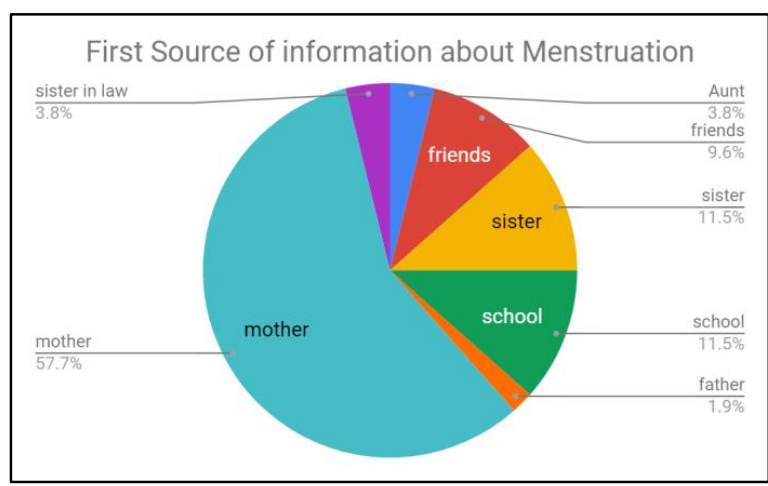

Approximately 48 percent of the respondents were aware about menstruation prior to their first experience, which they said prepared them mentally to a great extent. Majority of the respondents were only provided with practical knowledge i.e. how to manage menstruation, but the biological knowledge was not provided to them. Among the respondents who were informed about periods beforehand, it was done by their mothers. Many respondents were told by other significant women in their lives - sisters, cousins, friends, and sisters-in-law. Only 5.8 percent got this information from books. Graph 6 shows the exact percentage of the first source 
of information. Only one girl was informed about menstruation by her father, when her mother was at work. Vanita, a 21 year-old unmarried girl, daughter of a musician father and working mother, recalls her menarche experience. Her mother was away at work, and she had only her father to turn to:

I felt a little hesitant asking my father about it, but since we have open discussions at home regarding a lot of strange topics, I broached the topic. He explained the practical part of management of periods to me, and told me not to worry. It was quite awkward. I did feel a little confused and lost. He told me that periods occurred as they were a process of cleaning the blood in our body, but I wondered why the blood of boys did not need cleaning. It was much later that I found out from my school and friends that it was something entirely different. Even if my father didn't give me the exact knowledge, I was sure glad that he was supportive. That's the important thing.

Although her father had explained the process to her, the information was incorrect. Vanita's experience demonstrates how the cultural gulf between the sexes in our society does not allow a decent conversation between father and daughter on any topic related to sex, sexuality or reproduction. That is most probably the reason the father explained away menstruation as a monthly cleansing of the blood, rather than going into a lesson in biology.

\subsection{Menstrual Management and Hygiene}

Most of the respondents, i.e., 87.5 percent use sanitary pads during their periods. Apart from sanitary pads, tampons are also being used by some of the respondents. Being expensive, they are used by only 2.1 per cent of the women. Tampons are also not advertised and promoted by the manufacturers, as much as sanitary napkins. Graph 7 shows the various materials used by the women during menstruation. Only 10.4 percent of the respondents said they use cloth. However, none of the respondents re-used the same cloth. So, even among the women from the lower class, not all of them use cloth. Some of the older women find cloth more comfortable, as they were habitually using it since adolescence. Some of the young girls said that they used sanitary pads when they could afford it. At other times, they had to make do with cloth. Few girls said that they combined the pads and cloth during days of very heavy flow. Thus, sanitary napkins emerged as the most popular choice for menstrual management.

The frequency of changing pads is an important indicator of menstrual hygiene and brings to focus the use of public spaces by women. The average time that the respondents used a single pad for is 6.8 hours. However, there are various reasons when women find that they cannot 
change pads even if they want to. Since a woman must keep the periods a secret, she finds it tough in public places like school, college, office, travel, etc. Some women revealed that though they know they must change the pads frequently, they cannot do so. At other times, the place of study or work may not have proper toilets for girls. One respondent said that her long office hours meant that she can change a pad only after 11 hours. Around 23 per cent of rural schools have unusable toilets and 11.5 percent have no separate toilets for girls, according to the 13th Annual Status of Education Report (ASER) (Verma, 2019). This implies that some girls are forced to miss school every month, and some may be forced to drop out of school altogether (ASER) (Verma, 2019). This also reveals the significance of the cultural notion of shame in the everyday lives of women.

Graph 7: Materials used for menstrual management

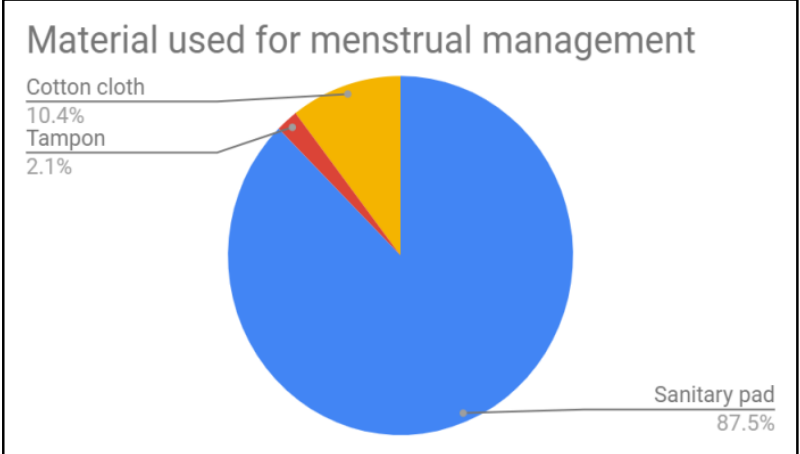

Graph 8: Physical problems experienced during menstruation

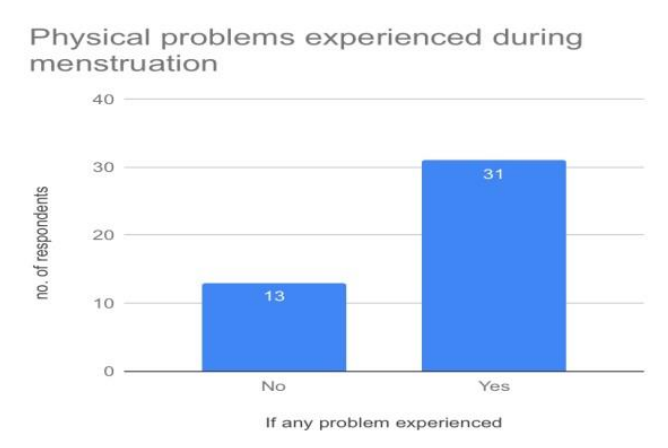

\subsection{Menstruation: the necessary evil?}

Out of 44 respondents, 31 said they faced pain and discomfort, whereas 13 said they do not experience any such problems. Graph 8 denotes whether respondents experienced any problem during menstruation. Respondents complained of menstrual cramps, vomiting, headaches, irregular menstrual cycles, bloating, heavy blood flow and sometimes fever. They usually take allopathic medicines for these problems. Sometimes the problem is so severe that they must take leave from school/ college/ work.

Apart from the physical pain and discomfort, most women expressed other negative emotions towards periods, too. More than 60 per cent respondents felt that menstruation was a recurrent "museebat" (trouble or problem). The narrative of menstruation is of a hindrance that affects women's lives. One teenager referred to it as a "necessary evil". One constant worry for all women and girls is the shame associated with staining her clothes in a public space. It is part 
of being, or rather "becoming", a woman, which reflects a larger set of norms that dictate how women should behave - down to the minutest detail.

The medical discourse on menstruation, as part of women's health, has been overly medicalized. In terms of everyday life, PMS or premenstrual syndrome is used in popular discourse to explain away anything ranging from an irritable mood to pains and discomfiture. There is an array of over-the-counter and prescribed medicines and drugs to deal with PMS and menstrual aches and pains. In case the problems persist or worsen, many women have to visit doctors, who order tests and prescribe medicines. One gynecologist respondent told us that the use of a single pad for a long time can cause lumps on the vaginal area which might lead to irritation. Unhygienic practices can cause reproductive tract infections, allergies, endometriosis, and pelvic inflammatory diseases, she said. This underlines the importance of communication on this issue.

\subsection{Respondents' awareness of media initiatives on menstruation}

While there is a lot of content on the Internet, easily accessible and shared on social media, it is not accessible to women across classes. There are some social media initiatives which urge people to break the silence and the taboos on menstruation. Some of the prominent ones are Touch the Pickle (Campaigns of the World, 2016), Menstrupedia (Menstrupedia 2016), \#happytobleed (Jeevika Trust, 2016), \#keepgirlsinschool (Keep Girls In School, 2017). Some of these initiatives are India-specific, while there are others in developed countries across the globe. Some are sponsored by sanitary napkin manufacturing companies, others by feminist organizations. Graph 9 depicts whether the respondents are aware about various initiatives taking place on social media.

Various initiatives on social media aim to normalize periods. Touch the pickle was a 'silent cry of revolution', asking women to break out of the period-related taboos that they have grown up with which are a hindrance to their overall growth (afaqs! news bureau, 2015). Menstrupedia is a fun and accessible comic-cum-guide for young girls to clear all their doubts related to menstruation. "Myth breaking and period positivity are our strategies, and we wanted to make it a comic book because it's inclusive," says Aditi Gupta, the founder of Menstrupedia (Haynes, 2016).

Out of the total, only 43.2 percent respondents said that they were aware of such initiatives. Almost 56 percent said that they have never heard of any initiatives on social media since they cannot access social media. This highlights social media as a highly effective medium with a very limited range. Only the educated, urban middle class people tend to access it. The poor 
women who need concrete support are ignored, and the middle class is targeted. The positive side is that appealing to the middle class or celebrity endorsements for normalizing periods give a certain aspirational value to this new attitude, and fights conservative and regressive forces.

Graph 9: Awareness of social media initiatives on menstruation

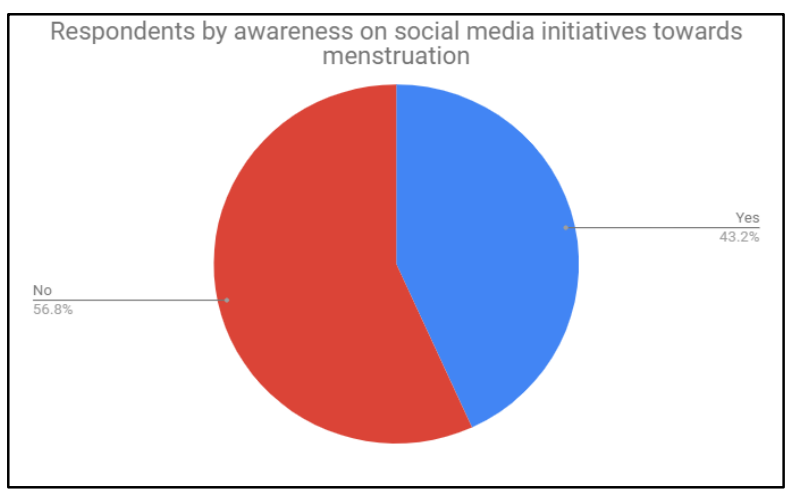

Graph 10: Respondents following restrictions and taboos

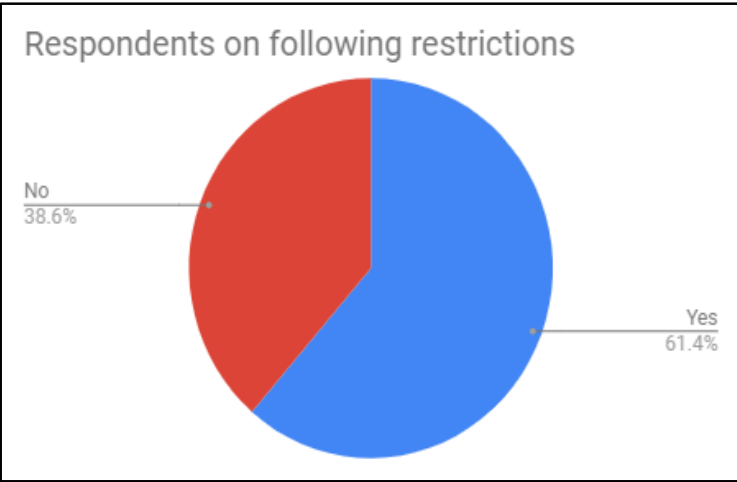

The reach and impact of electronic media like television are far greater than social media. The television advertisements of sanitary napkins bring visibility to the issue of menstruation. Some respondents said that they found it embarrassing to watch these advertisements with the entire family sitting together. Others said it is a product that must be promoted because the advertisements serve to bring awareness regarding the use of sanitary products. It gives visibility to an issue that society tends to render invisible. The advertisements show that it is normal for girls to go to school, or on a trip, or play sports during periods. In fact, they normalize periods, and show how normal lives of girls need not be disrupted because of periods. However, critics point out that these advertisements need to be made more educational. For example, all TV advertisements show blue liquid on a pad / tampon to depict blood. One girl was particularly perturbed by the blue liquid shown in these adverts, insisting that she failed to understand the purport of the advert as a child, and showing red liquid on the pad would have mentally prepared her for menarche. Despite the awareness being spread through social media and television, the deep-rooted taboos surrounding menstruation are difficult for young girls to break.

\subsection{Restrictions and taboos experienced during menstruation}

While 38.6 percent of the respondents said that they did not follow all the restrictions and taboos placed upon them during periods, this needs to be taken into perspective. Graph 10 
shows that 61.4 percent women followed the taboos. They were referring to all the restrictions. Most of the respondents followed some restrictions imposed by culture or religion. The restrictions placed on them ranged from forbidden food, visiting religious places of worship, cooking, having sex, etc. Most respondents followed the taboos regarding the places of worship as it is a matter of faith where one is not supposed to ask questions. Only Sikh women did not face any restrictions. Others were expected to follow them as a duty towards the family and religion. Mothers socialize their daughters into menstruation the way they were socialized by their mothers - with fear, anxiety, shame and silence. For example, one respondent said that when she was a member of a joint family and lived in the village, she followed the taboo on not cooking during menses. Now, having migrated to Delhi, and living in a nuclear family, she did not have any support system so that she could abstain from cooking. Her belief system still rested in the traditional mould, but her changed circumstances did not allow its practice to continue. This example shows how practices may change, without necessarily bringing about a concomitant change in beliefs. This is a reflection of how deep these taboos run, and how difficult it is to break free from them.

\section{DISCUSSION}

The present study highlights the fact that menstruation is not simply biological, but is strongly rooted in sociocultural norms and traditions. While many respondents have some knowledge about menstruation, it was not enough to empower them to talk freely about periods, not feel stigmatized, or not follow the taboos.

\subsection{The stigma and silences around menstruation: decoding menstruation through gender and patriarchy}

The silence around menstruation is part of a larger syndrome: the silencing of women, especially their bodies. For example, women must live anonymous lives under purdah, or that they should not leave their homes "unescorted" by a legitimate male chaperone, or that they should not make loud noises when undergoing labour pains! Women's bodies, their sexuality, and their voices are all suppressed by patriarchy (Chaudhary, 2011). The silence on menstruation is a mirror of this overarching structure of patriarchy.

In fact, women and men are all victims of patriarchy. Women are particularly subjugated. This involves all the aspects of menstruation - whether it is the restrictions, taboos, knowledge about menstruation, the silence, - all these aspects reflect the powerful patriarchal forces operative in our society. It promotes gender inequality by misplacing a health issue onto the arena of shame, stigma and taboo. Just as patriarchy silences the voices of women in various ways, it effectively 
silences them on menstruation. It uses the forced shame and silence and the taboos on mobility to control women's sexuality. By controlling their activities, mobility, and emotions, patriarchy effectively subjugates women - making them feel guilty about a biological process which is beyond human control.

Many respondents said that they were shocked at menarche, because they had no clue this would happen to them. Their mothers were silent on the issue, until menarche set in, and it became inevitable to talk about it. They had subsequent feelings of dirtiness, stress and anxiety. The cultural roots of the taboos and restrictions are internalized far more deeply than academic knowledge of biology gained at school. In other words, culture is easily internalized, and it becomes part of our belief system. What the school textbook imparts remains information outside ourselves. Everyday life is guided by religion and culture, not school textbooks. Thus, even the gynecologist interviewed, tried justifying the myths rather than dispelling them.

In addition to the taboos imposed by religion, most women have negative associations with menstruation. It is not simply because they are painful or inconvenient, but because of the social stigma on it imposed by culture. All girls are strongly told that it is something to be ashamed of, to hide, especially from men. One girl reported an incidence that many others would identify with:

“I remember a session being held by Whisper (a brand of sanitary pads) at school. Only the girls attended, and were told about menstruation. At the end of the session they gave us a pad each. You know, it was so difficult for us to take it back to the class as we couldn't let anybody see it, obviously. The boys asked us repeatedly what are you hiding; even one male teacher joined the questioning chorus of the boys. All of us just kept quiet and stared at the floor. I felt so ashamed"-

The girls were made to feel embarrassed for no reason at all. The session was perhaps only for the promotion of the brand, providing some basic information while omitting the most important part - periods are nothing to hide or be ashamed of. To the boys and men, all this seems like a joke. Boys bantering about it are often seen in movies. Apart from the girl whose father told her about periods, only one more girl had a heartening anecdote involving a male. She shared -

"We were coming back from school in the bus, when my best friend Rohit came and whispered in my ear that my skirt was stained. I was appalled. But, he neither smiled nor laughed. Rather, to my great surprise, he offered me his pullover to cover it. He even walked me home from the bus stop. I can never forget this. He was so supportive and positive. I told all my friends, and everybody appreciated his spirit." 
Such an occurrence is rare. Most girls said that if they want to discuss something about periods they usually get negative reactions from family and peers, and thus fall silent.

In the context of gender, we wondered "If menstruation was a male phenomenon, would it be treated in the same way as it is today?" Obviously not. All of us felt that if men had periods, it would probably be perceived as great pain and suffering. There would be much research and academic interest in the matter. Culturally, probably, it would be celebrated as a proof of fertility. Rather than shame and silence, it would be written about in books and magazines, depicted in art and sculpture, and would be seen as a great medical, social and human problem.

\subsection{The Perspective from Sociology of Health and Medicine}

The Sociology of Health and Medicine is critical of the medicalization of menstruation. Medicalization is the process of framing a normal biological process through pathologization and recognizing it as a health concern. The medicalization of menstruation has created the idea that periods are a problem that requires medical management by doctors rather than being considered a natural bodily function (Chekoudijan, 2009). Throughout history, menstruation has been considered to be a taboo and promotes a level of self consciousness influencing period shaming. The culture surrounding menstruation focuses on the biological aspects, perceiving periods as an undesirable bodily process. Biomedicine medicalizes menstruation to take the control and agency away from the women themselves. Doctors are the experts who decide what is normal and what is not, rather than the women, who would traditionally manage most of these problems through home remedies.

The term premenstrual syndrome (PMS) is defined as physical and psychological changes before and during menstruation that include fluid retention, acne, craving for sweet or salty food, aches and pains in the muscles or joints, fatigue, irritability, tension, anxiety, sadness, moodiness, feeling out of control, insomnia and alterations in sex drive (Chekoudijan, 2009) . PMS is an invention of biomedicine, and is heavily medicalized in developed countries, especially in the USA. The symptoms associated with PMS are many, and most of them are non-specific in nature - irritability, moodiness, discomfort, etc. Women are urged to consult a doctor if PMS affects their daily lives and activities. The same is true for menstruation and menopause. This approach, thus, seeks to take control of the lives of women from menarche to menopause.

The political economy perspective within the Sociology of Health and Medicine (Bird et al., 2010) argues that the emphasis on using sanitary napkins for menstrual management is a 
product of neoliberal capitalist pursuit of profit and profit alone. Most commercially available pads are produced by huge multinational corporations. Menstruation continues to be related to the commercial market and it is by default that associated information is provided to young girls. If menstrual hygiene products were produced locally by women using locally available resources -- as was shown by Arunachalam Muruganantham -- not only would it reduce costs, but also make these resources sustainable and easily available to underprivileged women.

From the point of view of the environment, sanitary napkins are not the best resource, as they are non-biodegradable. They are not environment friendly since they are made from cellulose and rayon - both synthetically developed substances. Environmentalists are encouraging women to try some environment-friendly alternatives to sanitary napkins. The biodegradable pads, the menstrual cup and reusable cloth pads are some alternatives available in the market, but are not popular yet.

There are some positive rays of hope in this bleak scenario. Organizations and individuals are working to make sustainable cheap sanitary products available to poor rural women. Prashant Sathe, a Fellow under the Chief Minister's Rural Development Fellowship Programme, has been mobilizing women from Self Help Groups (SHGs) to sell cotton pads and spread awareness about menstrual hygiene. He has managed to bring menstrual hygiene to the forefront in a place where the subject was never discussed (Shelar, 2018).

Arunachalam Muruganantham dedicated his life to develop a machine that makes low-cost sanitary pads for poor rural women. He struggled to fight the stigma and shame which dictates that men should have nothing to do with menstruation. He claims to have most difficulty with the superstitions surrounding menstruation, which he tries to overcome by educating women. A Hindi movie called "Pad Man" (2018) was made based on his life and journey. There are many others - individuals and organizations - working towards the empowerment of women through activism on menstruation.

\section{CONCLUSION}

Most cultures worldwide have surrounded menstruation with a stigma that is now proving very difficult to eradicate. Women are pressured to follow the taboos imposed on them by their families, religion and culture. Feminists and menstrual activists are actively engaged in this humongous effort worldwide. They have developed slogans like "The period is political" to highlight how contested this issue really is (Whittaker-Cumming, 2018). Women's health has been medicalized greatly, and biomedicine has covered every aspect of women's reproductive 
health from menarche to menopause. It further aids in the construction of menstruation as a negative, undesirable, and unwanted biological phenomenon. There is a need for women to regain control and agency over their bodies and their health, and build systems and communities of mutual support to manage not just menstruation, but much more. There is an urgent need to shift this discussion towards health of the women, by the women. There should be awareness about menstruation, and the stigma associated with it (through culture or biomedicine) should be completely negated, so that every woman can freely use locallyproduced, sustainable products for menstrual management, or engage in any bodily activities at the time. More than the limits set by society, the limits of the human body should decide the activities it is capable of performing during menstruation.

Moreover, this study, like so many others, has shown how education about menstruation does not lead to change in attitude or behavior. Women in India do not have effective communities or platforms to share their experience or know what is best for their health and hygiene. Media helps bring menstruation awareness to homes and public spaces, thus, helping to normalize it to some extent.

We propose that awareness on this issue should be included in the school curriculum so that children aged 10 years get accurate and adequate knowledge about it. It is important to share this knowledge not only with the girls, but also boys, so that it is destigmatized and normalized among the younger generation. Schools must provide sanitary napkins, free of cost, as is being done in government schools in Delhi. At the macro level, the government should work towards making menstrual management products completely free of cost.

Being able to manage menstruation safely and without stigma is a basic human right which many women and girls are denied. It is not ignorance that leads women to follow the cultural taboos, it is the internalization of traditional and religious norms. The silence and stigma around menstruation needs to be replaced by open and positive dialogue about it. It is important that experts develop communications which will bring about positive change in attitudes and behavior of the people. Such a change in attitude about menstruation cannot be achieved if it addresses menstruation alone. It can only be realised as part of a larger social transformation where men and women are equal.

\section{CONFLICT OF INTEREST}

There is no conflict of interest.

\section{SOURCE OF FUNDING}

Maitreyi College, University of Delhi 


\section{ACKNOWLEDGEMENT}

We express our heartfelt gratitude to Maitreyi College, University of Delhi, for providing us with the opportunity of conducting this research under the summer internship program, and also for publishing this paper in the e-journal.

\section{REFERENCES:}

Bird, C. E., Conrad, P., Fremont, A. M., \& Timmermans, S. (2010). Handbook of medical sociology (6th ed.). Vanderbilt University Press.

Chowdhry, P. (2011). Political economy of production and reproduction: Caste, custom, and community in North India. Oxford University Press, USA.

Chekoudjian, C. (2009). The subjective experience of PMS: A sociological analysis of women's narratives. Retrieved July 02, 2020, from https://scholarcommons.usf.edu/etd/1895/

Chowdhury, S. (2014). Why Menstruating Women Are Considered Impure In Hinduism. Boldsky Limitless. https://www.boldsky.com/yoga-spirituality/thought/2014/whymenstruating-women-are-considered-impure-042987.html

COTW Campaigns of the World. (2016, July 26). From Whisper Touch The Pickle: https://campaignsoftheworld.com/tv/whisper-touch-the-pickle

Durkheim, E. (1961). The elementary forms of the religious life. New York: Collier Books.

Garg, S., Sharma, N., \&Sahay, R. (2001) Socio-cultural aspects of menstruation in an urban slum in Delhi, India, Reproductive Health Matters. Taylor \& Francis. 9:17, 16-25. https://doi.org/10.1016/S0968-8080(01)90004-7

George, R. (2016). The other side to India's sanitary pad revolution. The Guardian.

https://www.theguardian.com/commentisfree/2016/may/30/idia-sanitary-pad-revolution$\underline{\text { menstrual-man-periods-waste-problem }}$

Ghai, S. (2015). Menstruation in Women: Reflecting back to historical perspectives. Blogspot. http://srishtighai1.blogspot.com/2015/01/?m=1

HappyToBleed - breaking menstrual taboos in India. (2016, Feburary 3). From trust Jeevika| village livelihood in India: https://www.jeevika.org.uk/happytobleed-breakingmenstrual-taboos-in-india/

Haynes, S. (2016, December 12). How an Indian Comic Book Is Teaching Girls About Their Periods. From TIME: https://time.com/4590678/menstrupedia-aditi-gupta-tabooindial 
afaqs! News Bureau. How Procter \& Gamble India touched the pickle, hearts and lives. (2015, July 7). Retrieved from: https://www.afaqs.com/news/marketing/44803_HowProcter--Gamble-India-touched-the-pickle-hearts-and-lives

Jensen, Lene (2015), The Oxford Handbook of Human Development and Culture, Oxford University Press.

Kaundal, M., \& Thakur, B. (2014). A Dialogue on Menstrual Taboo. Indian Journal of $\begin{array}{llll}\text { Community } & \text { Health. } & \text { 192-195. Retrieved }\end{array}$ from https://www.iapsmupuk.org/journal/index.php/IJCH/article/view/401

Keep Girls in School. (n.d.). From Instagram : https://www.instagram.com/explore/tags/keepgirlsinschool/?hl=en

Mead, M. (1928). Coming of age in Samoa: a psychological study of primitive youth for western civilisation. New York: Blue Ribbon Books.

Menstrupedia| Friendly guide to healthy periods. (n.d.). From The Menstrupedia Comic| The Friendly Guide to Periods for Girls : https://www.menstrupedia.com/

Nielsen, A. (2010). Sanitary Protection: Every Woman's Health Right. Community DevelopmentOrganisation, Plan India.

Period hygiene: You should change your sanitary napkin these many times. (2018, March 6). Times of India. https://timesofindia.indiatimes.com/life-style/health-fitness/photostories/period-hygiene-you-should-change-your-sanitary-napkin-these-manytimes/photostory/63184125.cms

School Health and Nutrition Division (SHND), D. o. (2018). Menstrual hygiene management of adolescent school girls and nuns. Thimpu, Bhutan: United Nations Childrens Fund (UNICEF).

Shelar, J. (2018). After Padman here comes Pad fellow. The Hindu. https://www.thehindu.com/news/national/after-padman-here-comes-the-padfellow/article22838381.ece\#: :text=Much\%20before\%20Akshay\%20Kumar's\%20 $\underline{\text { Padman,Mr. }}$

Taneja, R. (2017). One Man's 20-Year Crusade To Bring Sanitary Napkins ToRural Women. From NDTV| Every Life Counts: https://everylifecounts.ndtv.com/one-mans-20year-crusade-to-bring-cheap-sanitary-napkins-to-rural-women-10040

Torondel, B., Sinha, S., Mohanty, J. R., Swain, T., Sahoo, P., Panda, B., Nayak, A., Bara, M.,Bilung, B., Cumming, O., Panigrahi, P.\& Das, P. (2018).Association between unhygienic menstrual management practices and prevalence of lower reproductive 
tract infections: a hospital-based cross-sectional study in Odisha, India. BMC infectious diseases, 18(1), 473.https://doi.org/10.1186/s12879-018-3384-2

Verma, R. (2019). Building toilets in rural schools is not enough, they have to be usable too. DownToEarth.https://www.downtoearth.org.in/news/waste/building-toilets-inrural-schools-is-not-enough-they-have-to-be-usable-too-63017

Whittaker-Cumming. (n.d.). Periods are political - and powerful. Mother Nature Partnership. https://www.mothernaturepartnership.org/periods-are-political-and-powerful/

How to cite this article: Jalan, A., Baweja, H., Bhandari, M., Kahmei, S. \& Grover, A. (2020). A Sociological Study of the Stigma and Silences around Menstruation. Vantage: Journal of Thematic Analysis, 1(1), 47-65.

DOI: https://doi.org/10.52253/vjta.2020.v01i01.06

(C) The Author(s) 2020.

This work is licensed under a Creative Commons Attribution 4.0 International License which permits its use, distribution and reproduction in any medium, provided the original work is cited. 